\title{
Interaction between antimicrobial peptide CM15 and model cell membrane affected by CM15 terminal amidation and membrane phase state
}

\author{
Liang Ma, Yongsheng Luo, Yong-Hao Ma, Xiaolin Lu*
}

State Key Laboratory of Bioelectronics, School of Biological Science \& Medical

Engineering, Southeast University, Nanjing, 210096, Jiangsu Province, P. R. China
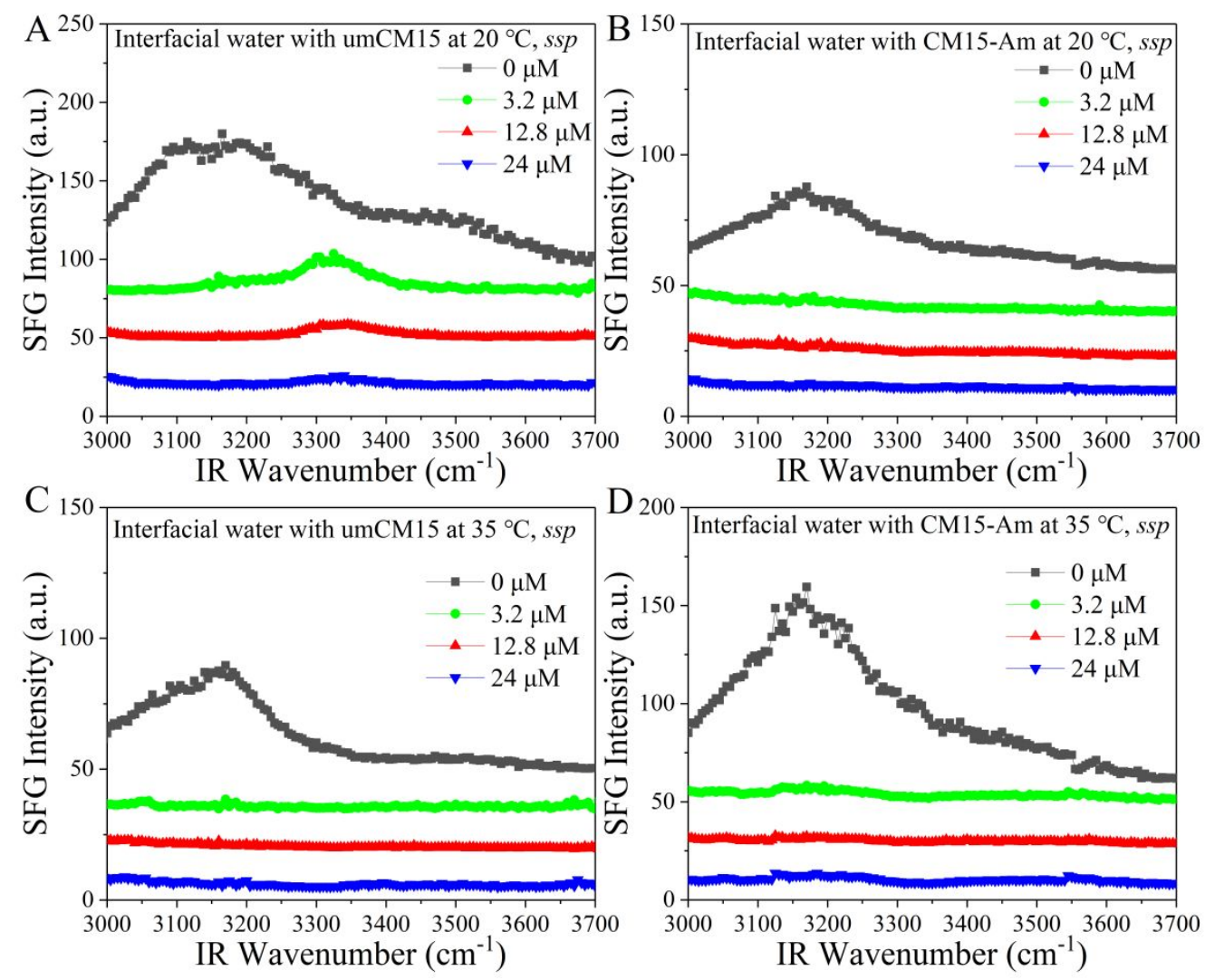

Figure S1. The SFG spectra of interfacial water signals with umCM15 (A) and

CM15-Am (B) at $\sim 20^{\circ} \mathrm{C}$, and umCM15 (C) and CM15-Am (D) at $\sim 35^{\circ} \mathrm{C}$. 


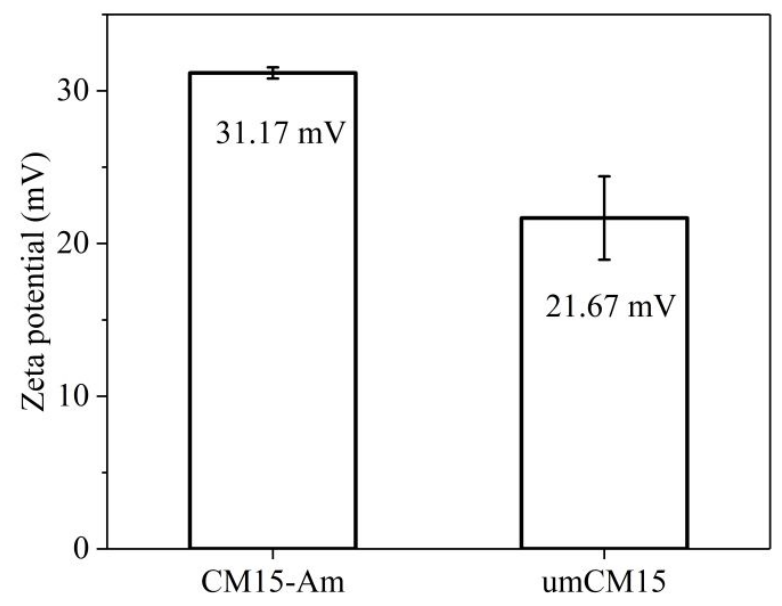

Figure S2. The zeta potentials of CM15-Am and umCM15 peptides $(1 \mathrm{mg} / \mathrm{ml})$ in deionized water measured with a Zetasizer Nano ZS instrument (Malvern Instruments, United Kingdom).
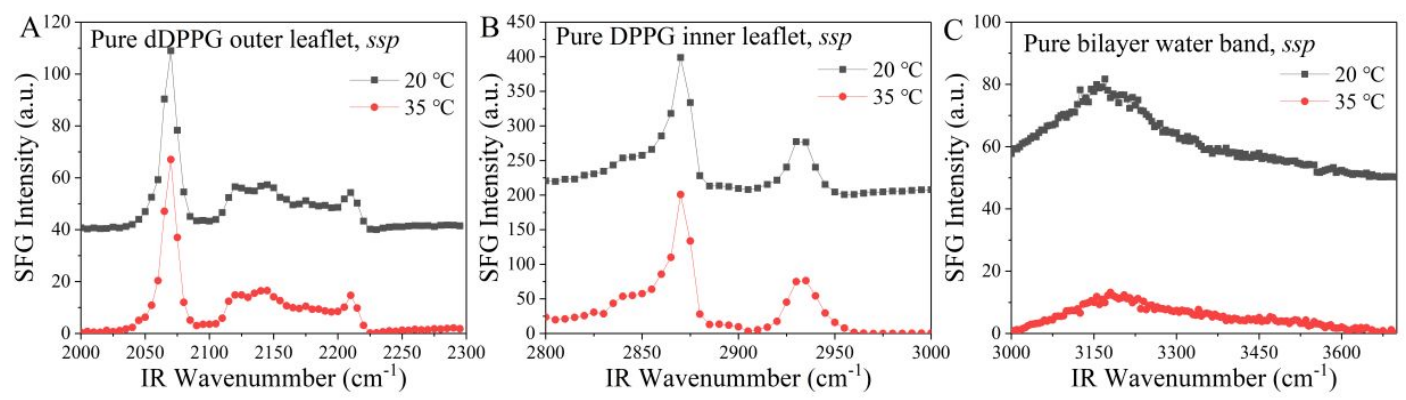

Figure S3. The SFG spectra of the DPPG-dDPPG bilayer in the CD range (A) and the $\mathrm{CH}$ range (B) at $\sim 20^{\circ} \mathrm{C}$ and $\sim 35^{\circ} \mathrm{C}$. The interfacial water $\mathrm{OH}$ signals (C) decreased a lot at $\sim 35^{\circ} \mathrm{C}$. 


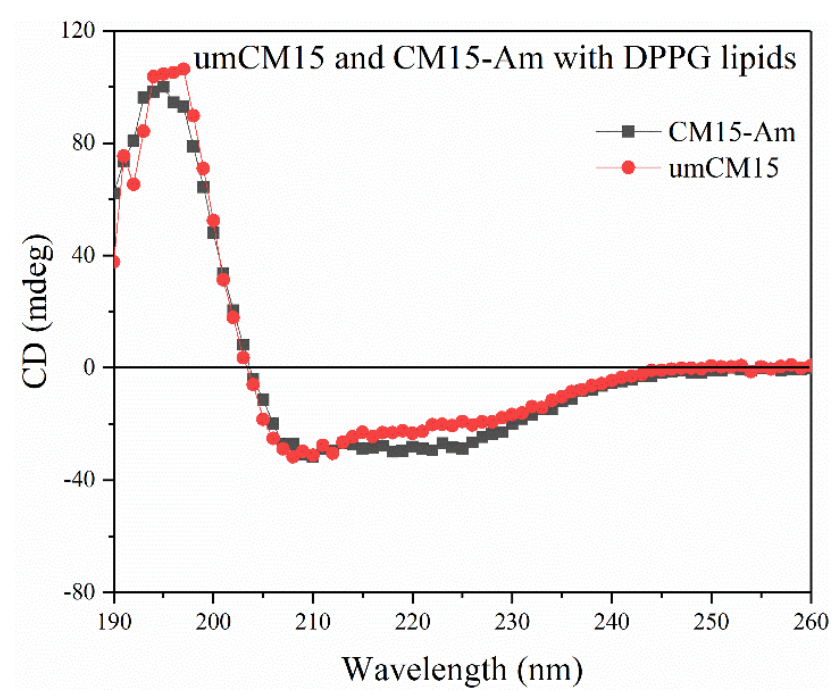

Figure S4. The CD spectra of CM15-Am and umCM15 in the presence of the DPPG lipids (liposomes) at $\sim 20^{\circ} \mathrm{C}$. 


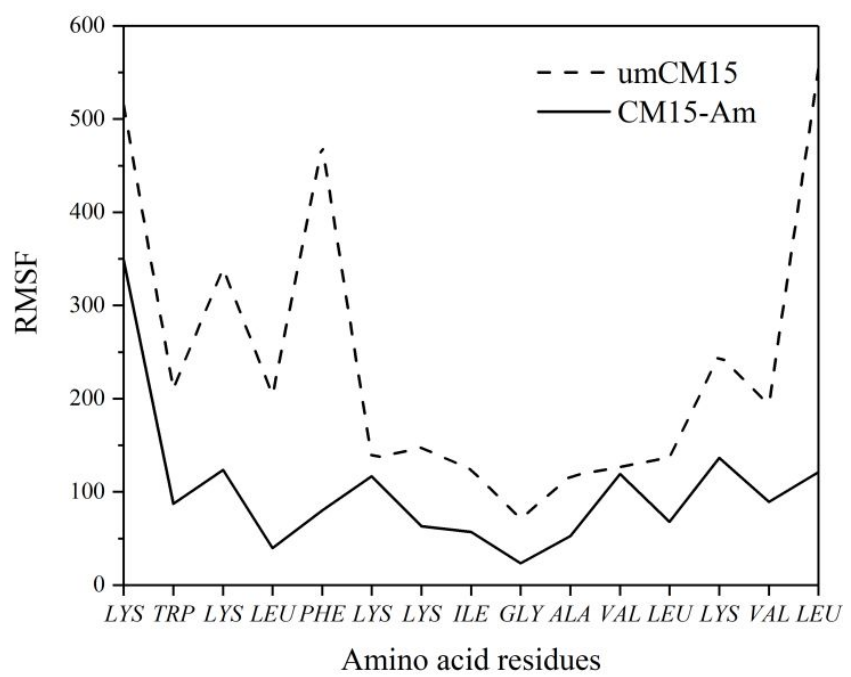

Figure S5. Root-mean-square fluctuation (RMSF) of umCM15 and CM15-Am via MD simulation. 

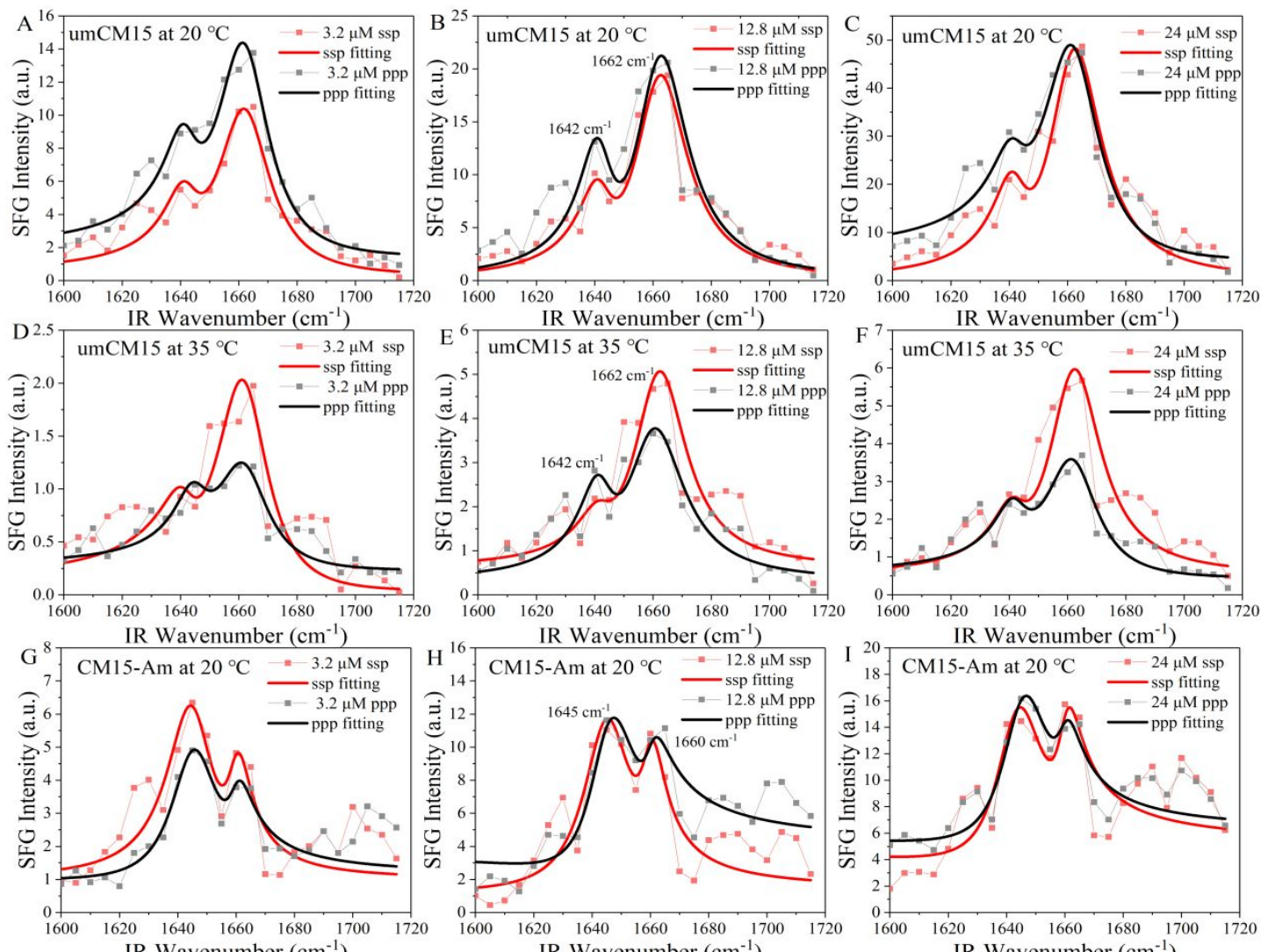

IR Wavenumber $\left(\mathrm{cm}^{-1}\right)$

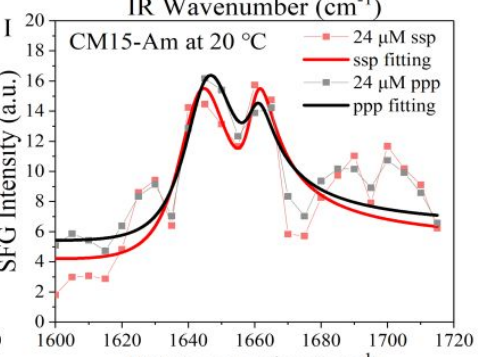

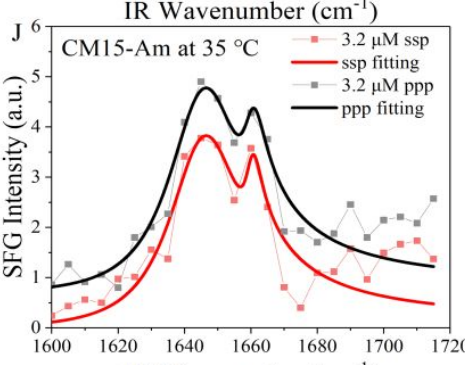

IR Wavenumber $\left(\mathrm{cm}^{-1}\right)$

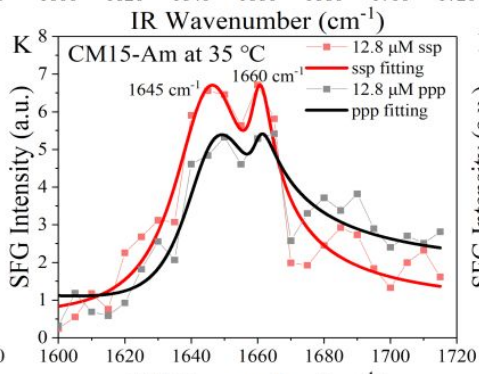

IR Wavenumber $\left(\mathrm{cm}^{-1}\right)$

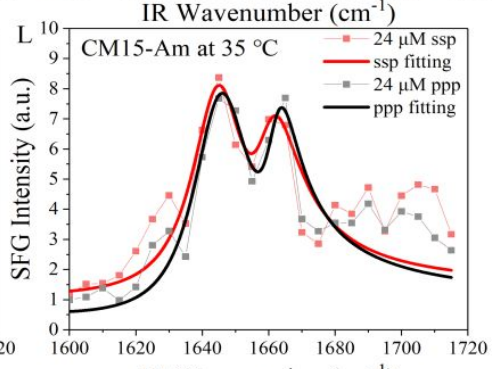

IR Wavenumber $\left(\mathrm{cm}^{-1}\right)$

Figure S6. The SFG spectra in the amide I range for the umCM15 and CM15-Am

solutions with concentrations of $3.2 \mu \mathrm{M}, 12.8 \mu \mathrm{M}$ and $24 \mu \mathrm{M}$ at $\sim 20^{\circ} \mathrm{C}$ and $\sim 35^{\circ} \mathrm{C}$. 